\title{
纳米-微米 $\mathrm{FeS}_{2}$ 晶须微形貌及其生长界面稳定性研究
}

\author{
黄菲 ${ }^{\circledR}$ ，王汝成 ${ }^{\circledR}$ ，张文兰 ${ }^{\circledR}$ ，姚玉增 ${ }^{\circledR}$, 彭艳东 $^{\circledR}$ ，寇大明 ${ }^{\circledR}$ \\ (1) 东北大学资源与土木工程学院, 沈阳 110004; \\ (2) 南京大学内生金属矿床成矿机制研究国家重点实验室, 南京 210008 \\ E-mail: huangfei@mail.neu.edu.cn
}

2009-04-16 收稿, 2009-08-25 接受

国家自然科学基金(批准号: 40872045)、内生金属矿床成矿机制研究国家重点实验室开放基金(批准号: 12-06-03)和地质过程与矿产资源国 家重点实验室开放基金(批准号: GPMR200906)资助项目

摘要 在前期天然纳米-微米 $\mathrm{FeS}_{2}$ 晶须研究基础上, 开展晶须微形貌观察研究. 发现不同时期 生长 $\mathrm{FeS}_{2}$ 晶须的密集程度、直径、表面微形貌有明显差别, 从早期到晚期晶须密集程度增加, 直 径减小, 表面微形貌呈现出结瘤突出 $\rightarrow$ 表面粗䊁 $\rightarrow$ 表面较光滑 $\rightarrow$ 表面平直、光洁的变化规律. 根据晶体生长理论、晶须形成的地质背景和地质作用方式, 分析讨论了耿庄 $\mathrm{FeS}_{2}$ 晶须结晶生长 时期生长界面稳定性及其变化过程. 认为晶须生长早期有负温度梯度和过冷出现, 晚期则是平 稳的正温度梯度状态. 晶须生长时期组分浓度经历了早期极不均匀, 中期阶段相对均匀, 晚期 较均匀的变化过程. 界面状态变化过程的总体趋势是由不稳定状态向稳定状态转变. 耿庄 $\mathrm{FeS}_{2}$ 晶须微形貌是热液体系中温度、组分浓度、界面相稳定性的协同作用结果. 晶须微形貌不仅反 映出晶须生长时期热液体系的物理、化学特点, 而且对界面相的稳定性特征反映特别明显, 记 录了晶须生长界面的变化过程.

关键词

$\mathrm{FeS}_{2}$ 晶须

表面微形貌

界面相稳定性
矿物是地质作用的基本产物, 其晶体形态及变 化状况既是内部原子排列规律的反映, 又是其生长 时环境变化历史过程的原始记录, 在地质体的产状 和成因研究中有重要意义. 近年研究发现, 晶体的微 形貌, 对于晶体内部缺陷和生长环境的变迁反映敏 感. 前人通过对辉钼矿、黄铁矿、方铅矿、䵢锡矿、 赤铁矿、自然金、辉锑锡铅矿、单斜铜泡石等矿物晶 面微形貌的观察, 发现了大量的阶梯状、螺旋状生长 结构和各种生长丘、生长纹, 以及晶体缺陷等.一些 研究者 ${ }^{[115]}$ 对采自热液矿床、实验合成黄铁矿和方铅 矿进行了微形貌观察, 探讨了矿物显微结构所传递 的成矿条件信息和动力学意义. 这些研究揭示出晶 体表面上各种精细图案与矿物生长条件、生长过程有 内在联系.
晶须是晶体生长的特殊形式, 代表了特定的生 长条件和生长机制 ${ }^{[16]}$. 虽然 Bonev 等人 ${ }^{[17]}$ 、 Galuskin ${ }^{[18]}$ 和 Bonev 等人 ${ }^{[19]}$ 发现过黄铁矿晶须, 并进 行过初步研究, 但有关黄铁矿晶须微形貌及生长界 面变化过程方面的研究还未见报道. 作者自 2004 年 在中国发现天然 $\mathrm{FeS}_{2}$ (包括黄铁矿和白铁矿) 以纳-微 米晶须方式生长以来, 通过扫描电子显微镜、电子探 针、拉曼光谱等手段研究发现, 纳米-微米级 $\mathrm{FeS}_{2}$ 晶 须形态多样, 生长现象丰富多彩, 成分和结构呈现规 律性变化, 并根据晶须生长理论, 结合地质环境和矿 区热液活动特点, 对 $\mathrm{FeS}_{2}$ 晶须的生长机理进行了分 析和探讨. 研究发现晶须矿物特征对地质环境非常 敏感, 在成矿地质条件分析等研究中有重要意 $义^{[20 \sim 24]}$.

深入研究 $\mathrm{FeS}_{2}$ 晶须表面微形貌特征, 可进一步 
了解晶体生长过程中更有价值的信息——界面的特 性、矿物个体生长发育历史、地质环境介质条件对纳 米-微米级 $\mathrm{FeS}_{2}$ 晶须结晶生长的影响、纳米-微米级 $\mathrm{FeS}_{2}$ 晶须矿物微观形貌变化与晶体生长过程的关联性 等新的科学内容. 对认识和理解纳米-微米矿物形成, 溶液体系中纳米-微米级矿物的结晶生长以及变化过 程也有启示 ${ }^{[25 ~ 29]}$. 本文在前期 $\mathrm{FeS}_{2}$ 晶须矿物基本特 征研究基础上, 根据 $\mathrm{FeS}_{2}$ 晶须微形貌观察结果, 结合 晶体生长理论, 分析讨论 $\mathrm{FeS}_{2}$ 晶须矿物表面微观形 貌与其生长界面条件之间的相互关系和动力学机理.

\section{$1 \mathrm{FeS}_{2}$ 晶须产状及主要特征}

样品产于山西耿庄金矿区含金隐爆角砾岩体晶洞 内的重晶石晶体中. 晶洞长 $2.8 \mathrm{~m}$, 宽 $1.5 \mathrm{~m}$, 高 $1.1 \mathrm{~m}$, 呈不规则的椭圆形. 晶洞直接围岩是热液注入角砾 岩, 角砾成分主要为花岗斑岩, 胶结物除岩粉、细岩 屑外, 还含有不少硫化物(黄铁矿、方铅矿、闪锌矿), 碳酸盐矿物及硅质成分. 晶洞壁角砾岩蚀变较强, 具 有流动构造(见图 1).

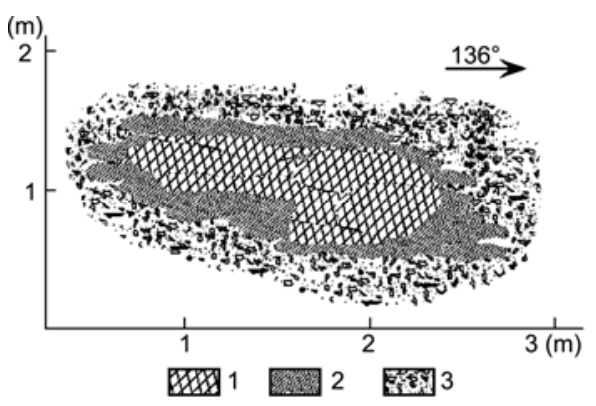

图 1 晶洞素描图

1 , 晶洞及重晶石晶体; 2 , 蚀变角砾岩; 3 , 角砾岩

重晶石晶体纯净透明, 颜色呈白色、淡黄、黄、 褐黄色, 许多晶体中心为白色, 向外出现淡黄-黄-褐 黄色分带现象.

$\mathrm{FeS}_{2}$ 晶须被包裹在重晶石中, 与重晶石之间为 共生-交互结晶的生长关系. $\mathrm{FeS}_{2}$ 晶须在重晶石中的 生长起点整齐, 取向非常明显, 定向性好, 从中心向 边缘, 垂直重晶石的(011), (101), (210)面向外生长. 构成了重晶石巨晶中非常明显的晶须环带. 观察发 现: $\mathrm{FeS}_{2}$ 晶须在重晶石晶体的不同部位生长特点明显 不同, 可分为 $\mathrm{a}, \mathrm{b}, \mathrm{c}, \mathrm{d}$ 四个区(带), 见图 2.

经电子探针分析, a 区(带)较粗 $\mathrm{FeS}_{2}$ 晶须中 $\mathrm{Ni}$, Co 的含量相对较高, Fe 的含量相对较低. b, c 区(带) 形态复杂的 $\mathrm{FeS}_{2}$ 晶须中 $\mathrm{Ni}, \mathrm{Co}$ 的含量相对降低, $\mathrm{Fe}$
的含量相对增加. d 区(带)形状简单的 $\mathrm{FeS}_{2}$ 晶须中 $\mathrm{Ni}$, Co 的含量较少, $\mathrm{Fe}$ 的含量则相对较高. 从早到晚 $\mathrm{FeS}_{2}$ 晶须中 $\mathrm{Ni}, \mathrm{Co}$ 的含量逐渐减少, $\mathrm{Fe}$ 的含量逐渐增 多(见表 1).

将含有 $\mathrm{FeS}_{2}$ 晶须样品制成双面抛光薄片, 在常 温下, 采用英国 Renishaw 公司, RM200型激光拉曼光 谱仪，分别测定了 a, b, c, d 区(带)内 $\mathrm{FeS}_{2}$ 晶须的拉曼 光谱, 将实测数据和拉曼谱图与 Renishaw 拉曼谱库 中黄铁矿、白铁矿特征参数进行对比. 结果显示: a 区(带)复杂形貌(较粗的藕节状、粗柱状)的 $\mathrm{FeS}_{2}$ 晶须 主要是白铁矿型结构; b, c 区(带)晶须中既有黄铁矿 型结构, 又有白铁矿型结构; $\mathrm{d}$ 区(带)简单形貌(平直、 表面光滑)的晶须是黄铁矿型结构(见图 3).

\section{$2 \mathrm{FeS}_{2}$ 晶须微形貌特征}

耿庄 $\mathrm{FeS}_{2}$ 晶须形貌丰富, 特点突出, 见图 2(b) (h). a 区 $\mathrm{FeS}_{2}$ 晶须与黄铁矿晶体混生在一起, 数 量较少, 长度差异较大, 短的 $120 \mu \mathrm{m}$, 最长 $600 \mu \mathrm{m}$, 一般 150 200 $\mu \mathrm{m}$, 直径达 30 50 $\mu \mathrm{m}$, 断面主要呈不规 则圆形、椭圆形, 少量三角形、矩形, 长径比在 10 30 之间. b, c 区 $\mathrm{FeS}_{2}$ 晶须数量有所增多, 形貌变化很大, 不仅相邻晶须会出现多种形貌，而且在同一根晶须的 不同部位上也有不同形貌出现，长、径尺度变化较大, 最长达 $1500 \mu \mathrm{m}$, 短的仅 $400 \mu \mathrm{m}$, 直径介于 5 30 $\mu \mathrm{m}$ 之间, 断面呈不规则圆形、椭圆形, 有规则三角形、矩 形、正方形出现，长径比达 50 300. d 区 $\mathrm{FeS}_{2}$ 晶须长 度主要在 800 1200 $\mu \mathrm{m}$ 范围内, 部分达到 $1800 \mu \mathrm{m}$, 少量超长晶须达到 $15 \mathrm{~mm}$, 直径差异不大, 平均 3 5 $\mu \mathrm{m}$, 部分 1 3 $\mu \mathrm{m}$, 少量极细的到 300 500 nm, 断面 主要呈较规则的三角形、矩形、正方形, 长径比主要 在 300 500 之间. d 区 $\mathrm{FeS}_{2}$ 晶须密集分布, 数量众多, 是本次发现晶须的主要类型.

a 区粗大 $\mathrm{FeS}_{2}$ 晶须表面极不平整，凸凹显著. b 区 $\mathrm{FeS}_{2}$ 晶须单体主要是藕节状、蒲棒状等, 粗大, 结 瘤突出、大小县殊, 差异明显. c 区 $\mathrm{FeS}_{2}$ 晶须表面较 粗䊁, 但与 b 区相比, 直径变小, 表面虽有结瘤, 但 相对均匀, 呈竹节状、串珠状. d 区 $\mathrm{FeS}_{2}$ 晶须表面虽 有起伏, 但表面已较光滑, 大量 $\mathrm{FeS}_{2}$ 晶须已经成为平 直光滑的直线状. $\mathrm{FeS}_{2}$ 晶须表面微观形貌分为: 具有 结瘤; 表面粗粘; 表面较光滑; 表面平直、光洁几种 类型. 总体呈现出从早到晚由结瘤突出 $\rightarrow$ 表面粗粘 $\rightarrow$ 表面较光滑 $\rightarrow$ 表面平直、光洁的变化规律. 

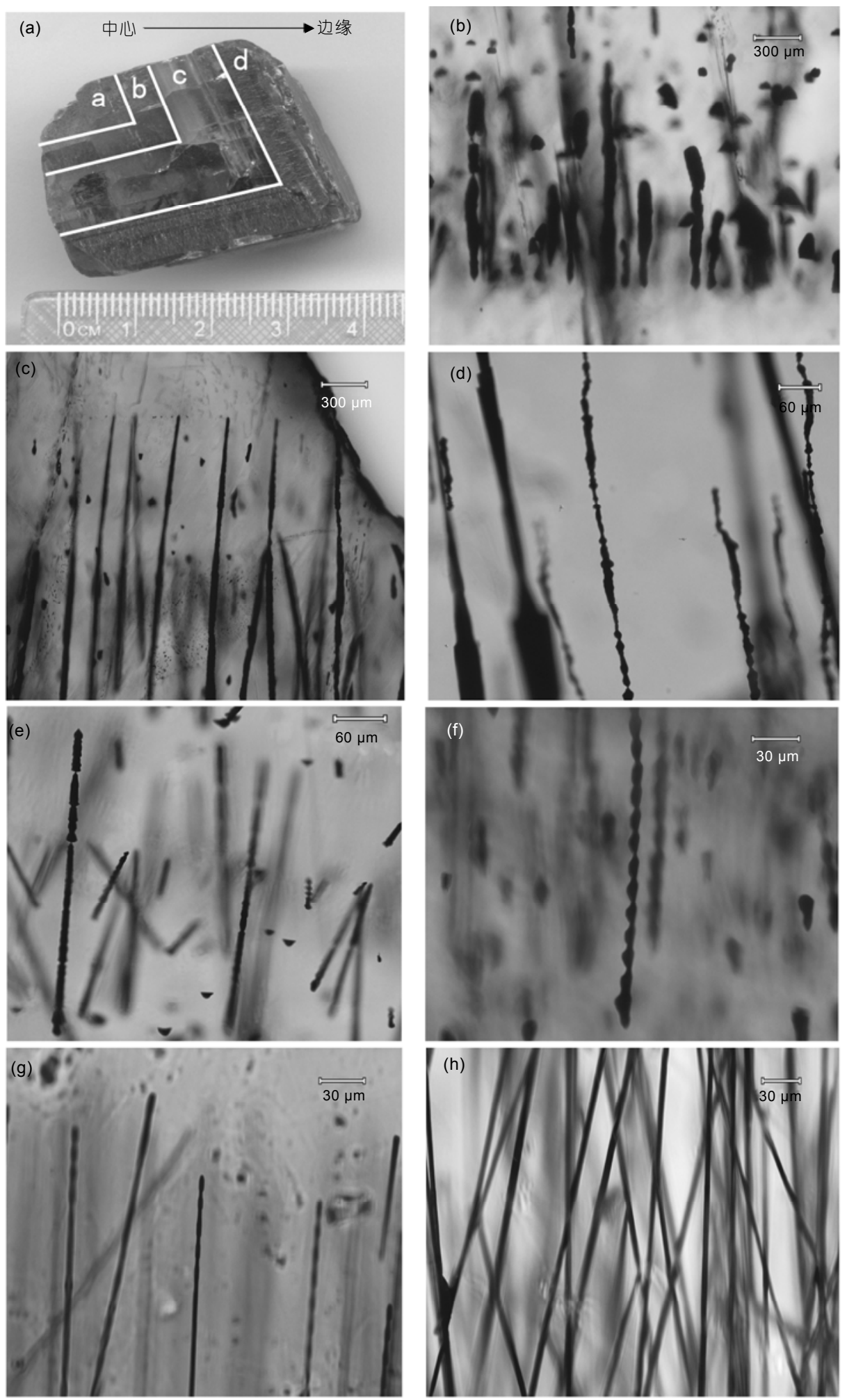

图 2 重晶石晶体和晶须的多种形貌

(a) 含晶须的重晶石晶体; (b) a 区仅有少量晶须, 其粗大、结瘤突出, 并与晶体混生; (c) b 区稀疏分布的晶须定向排列成粗棒状, 表面粗徙; (d) b 区稀疏分布的晶须较粗、结瘤明显; (e) c 区稀疏分布的晶须表面较粗䊅; (f) c 区较稀疏分布的晶须成串珠状; (g) d 区部分晶须的表面略有突出; (h) d 区大量密集分布的晶须表面平直、光洁 
表 $1 \mathrm{FeS}_{2}$ 晶须成分的电子探针分析结果 ${ }^{\mathrm{a})}(\mathrm{wt} \%)$

\begin{tabular}{|c|c|c|c|c|c|c|c|c|c|c|}
\hline 序号 & 样号 & 形状 & S & $\mathrm{Fe}$ & Co & $\mathrm{Ni}$ & As & 总量 & 矿物分子式 & 位置 \\
\hline 1 & QJ-1-6 & 粗柱状 & 52.31 & 21.25 & 8.07 & 18.07 & 0.29 & 100 & $\left(\mathrm{Fe}_{0.4638} \mathrm{Ni}_{0.3752} \mathrm{Co}_{0.1668}\right)_{1.0058} \mathrm{~S}_{2}$ & \multirow{9}{*}{ a 区 } \\
\hline 2 & QJ-1-7 & 粗柱状 & 52.78 & 20.04 & 8.09 & 18.93 & 0.17 & 100 & $\left(\mathrm{Fe}_{0.4346} \mathrm{Ni}_{0.3904} \mathrm{Co}_{0.1662}\right)_{0.9525} \mathrm{~S}_{2}$ & \\
\hline 3 & QJ-1-8 & 粗柱状 & 52.73 & 18.76 & 8.21 & 19.87 & 0.43 & 100 & $\left(\mathrm{Ni}_{0.4082} \mathrm{Fe}_{0.4051} \mathrm{Co}_{0.1680}\right)_{0.9813} \mathrm{~S}_{2}$ & \\
\hline 4 & QJ-1-9 & 粗柱状 & 52.92 & 19.32 & 8.71 & 19.04 & 0.02 & 100 & $\left(\mathrm{Fe}_{0.4190} \mathrm{Ni}_{0.3928} \mathrm{Co}_{0.1790}\right)_{0.9908} \mathrm{~S}_{2}$ & \\
\hline 5 & QJ-1-10 & 粗柱状 & 53.16 & 26.25 & 3.39 & 17.17 & 0.03 & 100 & $\left(\mathrm{Fe}_{0.5667} \mathrm{Ni}_{0.3525} \mathrm{Co}_{0.0693}\right)_{0.9885} \mathrm{~S}_{2}$ & \\
\hline 6 & ZX-1-9 & 火焰状 & 52.93 & 27 & 3.12 & 16.81 & 0.14 & 100 & $\left(\mathrm{Fe}_{0.5853} \mathrm{Ni}_{0.3468} \mathrm{Co}_{0.0640}\right)_{0.9961} \mathrm{~S}_{2}$ & \\
\hline 7 & ZX-1-10 & 火焰状 & 53.58 & 29.15 & 2.6 & 14.67 & 0 & 100 & $\left(\mathrm{Fe}_{0.6247} \mathrm{Ni}_{0.2989} \mathrm{Co}_{0.0527}\right)_{0.9763} \mathrm{~S}_{2}$ & \\
\hline 8 & ZX-1-11 & 火焰状 & 53.35 & 28.7 & 3.09 & 14.85 & 0.02 & 100 & $\left(\mathrm{Fe}_{0.6176} \mathrm{Ni}_{0.3039} \mathrm{Co}_{0.0629}\right)_{0.9845} \mathrm{~S}_{2}$ & \\
\hline 9 & ZX-1-12 & 火焰状 & 53.14 & 28.81 & 2.98 & 15.02 & 0.05 & 100 & $\left(\mathrm{Fe}_{0.6225} \mathrm{Ni}_{0.3086} \mathrm{Co}_{0.0609}\right)_{0.9920} \mathrm{~S}_{2}$ & \\
\hline 10 & HD-10-2 & 蒲棒状 & 53.3 & 23.5 & 6 & 17.05 & 0.15 & 100 & $\left(\mathrm{Fe}_{0.5062} \mathrm{Ni}_{0.3493} \mathrm{Co}_{0.1224}\right)_{0.9779} \mathrm{~S}_{2}$ & \multirow{10}{*}{$\mathrm{b} \sim \mathrm{c}$ 区 } \\
\hline 11 & HD-10-6 & 粗柱状 & 53.34 & 26.97 & 2.8 & 16.76 & 0.14 & 100 & $\left(\mathrm{Fe}_{0.5805} \mathrm{Ni}_{0.3431} \mathrm{Co}_{0.0571}\right)_{0.9807} \mathrm{~S}_{2}$ & \\
\hline 12 & HD-10-7 & 粗柱状 & 53.56 & 26.78 & 3.17 & 16.48 & 0 & 100 & $\left(\mathrm{Fe}_{0.5744} \mathrm{Ni}_{0.3360} \mathrm{Co}_{0.0642}\right)_{0.9746} \mathrm{~S}_{2}$ & \\
\hline 13 & HD-10-4 & 蒲棒状 & 53.15 & 28 & 3.2 & 15.65 & 0 & 100 & $\left(\mathrm{Fe}_{0.6049} \mathrm{Ni}_{0.3217} \mathrm{Co}_{0.0655}\right)_{0.9921} \mathrm{~S}_{2}$ & \\
\hline 14 & HD-10-8 & 串珠状 & 52.59 & 28.68 & 2.7 & 15.79 & 0.24 & 100 & $\left(\mathrm{Fe}_{0.6262} \mathrm{Ni}_{0.3278} \mathrm{Co}_{0.0558}\right)_{1.0098} \mathrm{~S}_{2}$ & \\
\hline 15 & HD-10-10 & 串珠状 & 52.65 & 29.71 & 2.78 & 14.86 & 0 & 100 & $\left(\mathrm{Fe}_{0.6479} \mathrm{Ni}_{0.2903} \mathrm{Co}_{0.0573}\right)_{0.9955} \mathrm{~S}_{2}$ & \\
\hline 16 & HD-10-3 & 蒲棒状 & 52.68 & 29.18 & 3.18 & 14.91 & 0.05 & 100 & $\left(\mathrm{Fe}_{0.6360} \mathrm{Ni}_{0.3090} \mathrm{Co}_{0.0656}\right)_{1.0106} \mathrm{~S}_{2}$ & \\
\hline 17 & HD-10-11 & 串珠状 & 53.17 & 30.23 & 2.6 & 13.95 & 0.05 & 100 & $\left(\mathrm{Fe}_{0.6521} \mathrm{Ni}_{0.2862} \mathrm{Co}_{0.0531}\right)_{0.9914} \mathrm{~S}_{2}$ & \\
\hline 18 & HD-10-5 & 粗柱状 & 53.87 & 32.2 & 1.65 & 12.28 & 0 & 100 & $\left(\mathrm{Fe}_{0.6863} \mathrm{Ni}_{0.2488} \mathrm{Co}_{0.0332}\right)_{0.9683} \mathrm{~S}_{2}$ & \\
\hline 19 & HD-10-9 & 直杆状 & 54.15 & 42.87 & 0.43 & 2.55 & 0 & 100 & $\left(\mathrm{Fe}_{0.9090} \mathrm{Ni}_{0.0514} \mathrm{Co}_{0.0085}\right)_{0.9689} \mathrm{~S}_{2}$ & \\
\hline 20 & F-10-1 & 直杆状 & 52.7 & 34.49 & 4.29 & 8.51 & 0.01 & 100 & $\left(\mathrm{Fe}_{0.7513} \mathrm{Ni}_{0.1762} \mathrm{Co}_{0.0884}\right)_{1.0159} \mathrm{~S}_{2}$ & \multirow{5}{*}{$\mathrm{d}$ 区 } \\
\hline 21 & F-10-2 & 直杆状 & 53.09 & 34.89 & 3.62 & 8.4 & 0 & 100 & $\left(\mathrm{Fe}_{0.7545} \mathrm{Ni}_{0.1727} \mathrm{Co}_{0.0741}\right)_{1.0013} \mathrm{~S}_{2}$ & \\
\hline 22 & F-10-3 & 直杆状 & 52.34 & 35.01 & 4.18 & 8.26 & 0.22 & 100 & $\left(\mathrm{Fe}_{0.7652} \mathrm{Ni}_{0.1716} \mathrm{Co}_{0.0865}\right)_{1.0233} \mathrm{~S}_{2}$ & \\
\hline 23 & F-10-4 & 直杆状 & 54.02 & 34.26 & 3.68 & 8.05 & 0 & 100 & $\left(\mathrm{Fe}_{0.7281} \mathrm{Ni}_{0.1627} \mathrm{Co}_{0.0740}\right)_{0.9648} \mathrm{~S}_{2}$ & \\
\hline 24 & $\mathrm{~F}-10-5$ & 直杆状 & 54.31 & 34.67 & 2.8 & 8.04 & 0.17 & 100 & $\left(\mathrm{Fe}_{0.7305} \mathrm{Ni}_{0.1611} \mathrm{Co}_{0.0559}\right)_{0.9477} \mathrm{~S}_{2}$ & \\
\hline
\end{tabular}

a) 分析者: 舒桂明, 北京大学造山带与地壳演化教育部重点实验室, 电子探针实验室; 仪器型号：JXA-8100; 分析条件：加速电压 $15 \mathrm{kV}$; 束流 $1 \times 10^{-8} \mathrm{~A}$; 束斑 $1 \mu \mathrm{m}$; 修正方法 PRZ; 标准样品美国 SPI 公司 53 种矿物
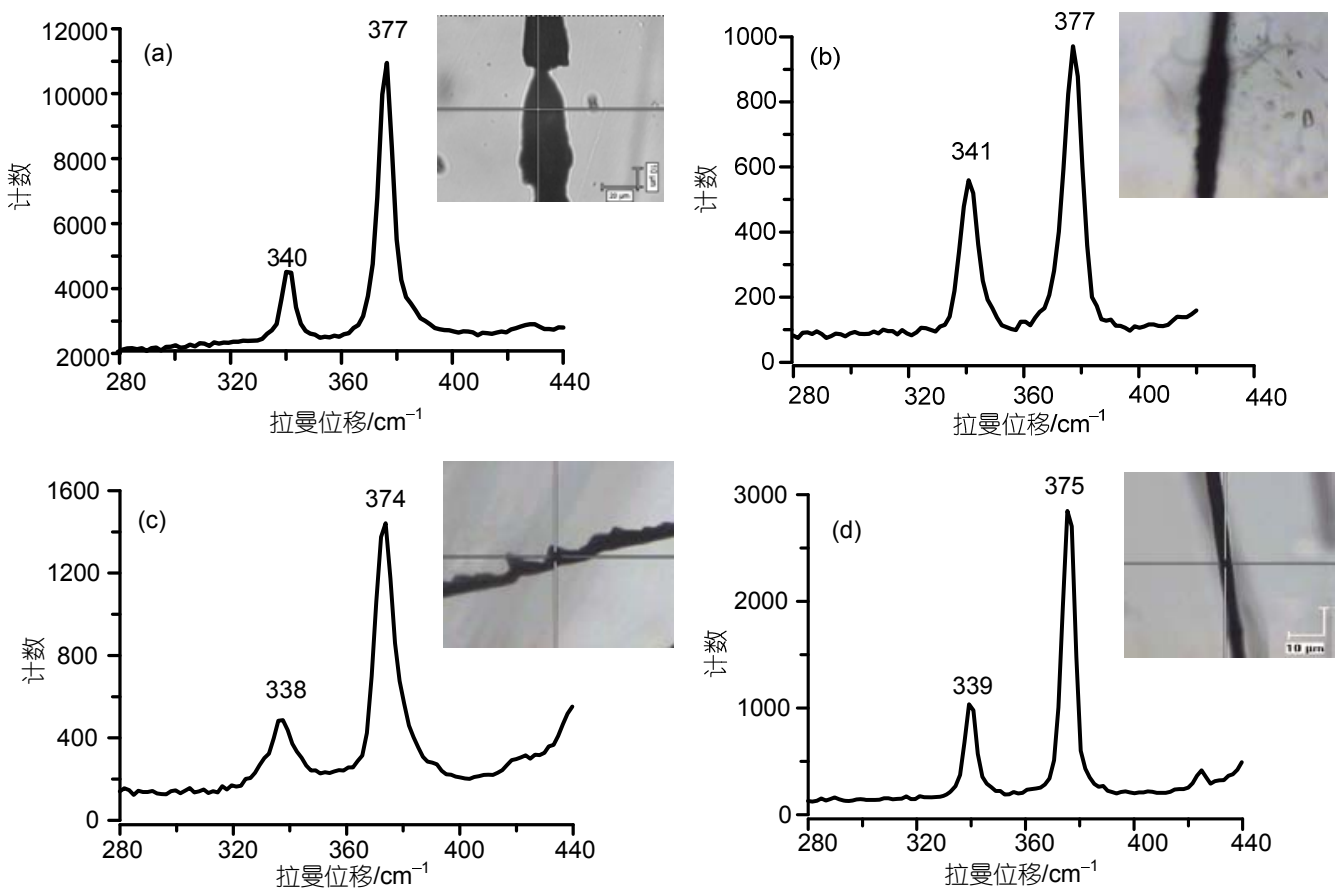

图 3 不同形貌 $\mathrm{FeS}_{2}$ 晶须的拉曼谱图

(a) a 区藕节状晶须及谱图; (b) b 区粗柱状晶须及谱图; (c) c 区火焰状晶须及谱图; (d) d 区直线状晶须及谱图 


\section{3 分析与讨论}

耿庄 $\mathrm{FeS}_{2}$ 晶须产于隐爆角砾岩的晶洞内, 由火 山隐爆作用形成, 热液是富含多组分复杂溶液的低 温流体, 有脉动特点. 主要成分有水、被溶解的气体 $\left(\mathrm{H}_{2} \mathrm{~S}, \mathrm{CO}_{2}\right.$ 和 $\left.\mathrm{O}_{2}\right)$, 以及成易溶化合物带出的碱和碱土 金属 $\mathrm{Na}, \mathrm{K}, \mathrm{Ca}, \mathrm{Mg}$ 和阴离子 $\mathrm{Cl}^{-}, \mathrm{BO}_{3}^{2-}, \mathrm{HCO}_{3}^{-}, \mathrm{SO}_{4}^{2-}$ 等. 这种复杂多组分系统的化学平衡对外在因素(温 度、压力, Eh 等)的变化极其敏感.

在晶体成核作用讨论中, Hirth 等 ${ }^{[30]}$ 提出当下述 等式成立时, 成核作用便开始进行:

$$
(P / P e) c r i t=\exp \left(\pi h \Omega \gamma^{2} 65 \kappa^{2} T^{2}\right),
$$

式中 $h$, 成核台阶的高 $(\mathrm{m}) ; \gamma$, 晶体的表面能 $(\mathrm{m}) ; \Omega$, 分子体积 $\left(\mathrm{m}^{3}\right) ; \kappa$, 玻尔兹曼常数, $1.38 \times 10^{-23} \mathrm{~J} / \mathrm{K} ; T$, 热力学温度 $(\mathrm{K})$.

晶核形成后就形成了晶体一介质的界面, 界面状 态将直接影响在界面上发生的晶体生长过程. 通常 情况下, 界面粗䊁度越大, 生长速率越大, 易形成胞 状晶体; 而当界面粗粘度越小时, 生长速率就越小, 形成的是光滑界面. 界面的稳定性主要与温度梯度 和浓度梯度有关 ${ }^{[31]}$ (图 4 和 5).

正温度梯度下, 生长界面保持为平滑面, 如果偶 然发生局部凸出生长, 则预示已经进入了高于 $T_{\mathrm{m}}$ 的

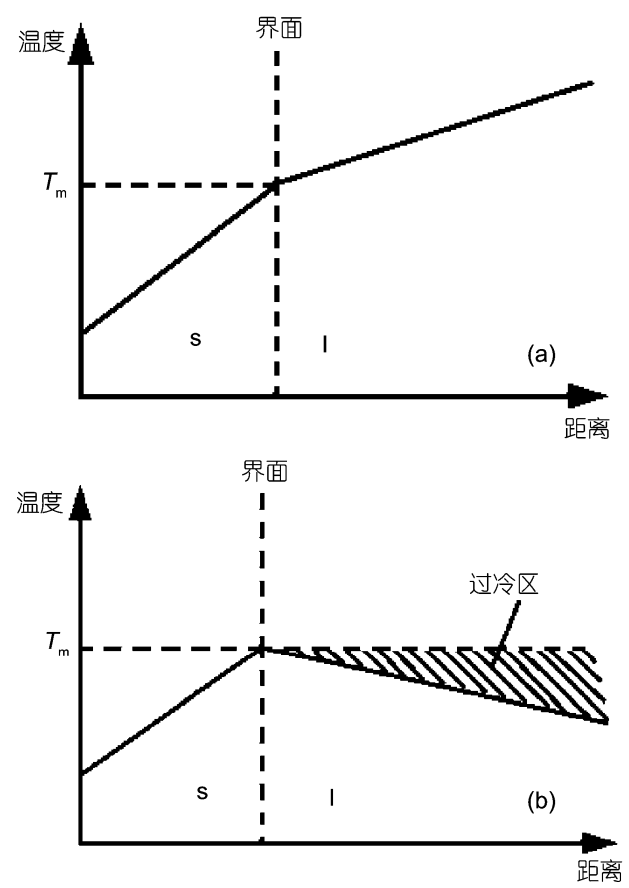

图 4 固-液界面前沿液体的温度分布

(a) 正温度梯度, (b) 负温度梯度 ${ }^{[31]}$

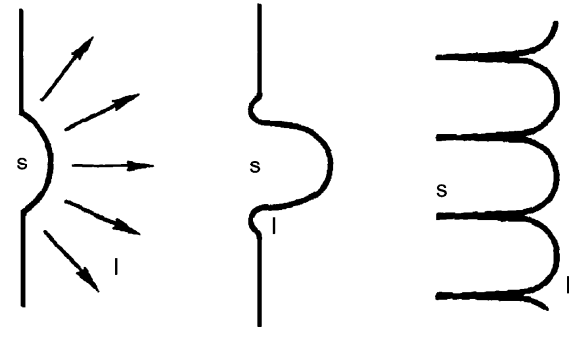

图 5 胞状组织示意图 $[31]$

高温区域会被溶化, 所以偶然的涨落、微扰形成的凸 出部分是不稳定的, 生长界面能始终保持平滑的、平 衡的状态.

负温度梯度情况下, 界面上一旦形成了凸出部 分, 这一凸出部分就进人比 $T_{\mathrm{m}}$ 更低的低温区, 更加 快凸出部分的快速生长, 结果就导致了胞状组织的 形成.

当晶体生长体系为多组分体系, 或生长体系中 含有杂质元素时, 晶体生长会产生分凝效应, 即某元 素在晶体与液体中的浓度不等. 设在晶体中的浓度 $\mathrm{Cs}$ 小于在液体中的浓度 $\mathrm{Cl}$, 随着晶面生长前移, 界 面前沿该元素的浓度将提高, 形成了界面前沿液体 中的浓度梯度(见图 6). 该元素浓度的提高会改变凝 固点温度, 一般都会使凝固点下降. 这时, 界面前沿 液体中有两个温度分布(见图 7). $T_{1}$ 为液相线的温度 分布, 即靠近界面液相线温度(即凝固点)下降, $T_{1}$ 是 实际温度分布, 即为上述的正温度梯度. 在界面前沿 有一个区域, 实际温度 $T_{1}$ 小于液相线温度 $T_{1}$, 造成界 面前出现过冷现象, 这种由成分分布变化而引起的 过冷现象叫成分过冷或组分过冷. 同样, 组分过冷现 象也会使界面上偶然的凸出部分快速生长而形成枝 晶, 当组分过冷较小时, 则会形成胞状组织. 但如果 正温度梯度非常大, 如图示的 $T_{2}$, 则不会产生组分过 冷现象.

耿庄 $\mathrm{FeS}_{2}$ 晶须微形貌特征显示, 在不同的形成 和生长时期, $\mathrm{FeS}_{2}$ 晶须微形貌有明显差异, 分别代表 了生长界面的不同状态.

重晶石晶体生长的早期阶段(a 区形成时期), 是 热液涌入的早期阶段, 热液进入晶洞这个相对开放 的体系, 降温速率过快, 造成热液状态不稳, 界面前 沿元素的浓度较高, 负温度梯度和组分过冷变化较 大, 在 $\mathrm{FeS}_{2}$ 晶须生长过程中, 生长界面上形成胞状组 织, 使表面生长成为结、瘤突出的粗粘晶面, 界面状 态极不稳定. 


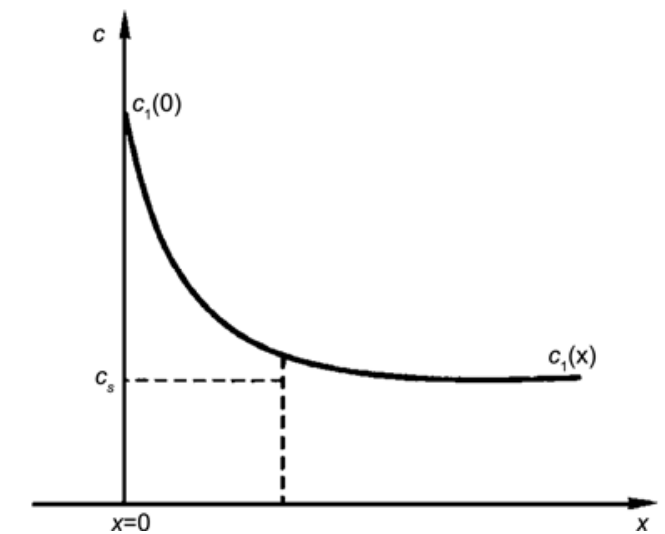

图 6 界面沿某元素的浓度分布 $[31]$

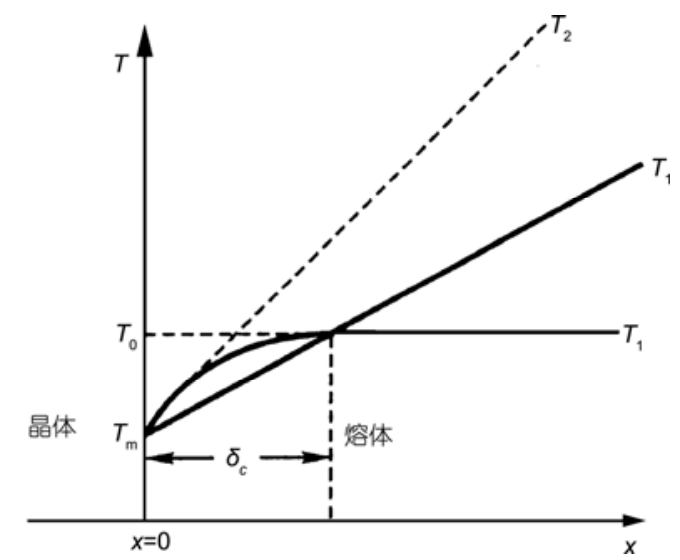

图 7 界面前沿各种温度分布 $[31]$

重晶石晶体生长的中期阶段(b，c 区形成时期), 热液继承了先期热液特点, 但降温速率有所减缓, 界 面前沿元素的浓度相对降低, 负温度梯度和组分过 冷变化减弱, 虽然在晶须生长过程中界面上形成胞 状组织出现, 但晶须直径减小, 表面虽然粗粘, 但有 相对平整的棒状晶须出现，界面呈亚稳定状态. 重晶石晶体生长的晚期阶段(d 区形成时期), 热 液演化到了晚期阶段, 界面前沿元素的浓度较低, 分 布较均匀. 由于晶洞封闭保温, 使热液保持了正温度 梯度状态, 生长界面能始终保持平滑的、平衡状态, 晶须生长界面保持为平滑面. 形成的晶须表面光滑、 平整.

\section{4 结论}

通过耿庄 $\mathrm{FeS}_{2}$ 晶须微形貌研究, 结合其生长地 质作用和背景条件分析, 获得以下结论:

(1) 耿庄 $\mathrm{FeS}_{2}$ 晶须微形貌记录了形成时期热液 状态、生长界面变化过程及其稳定性特点.

(2) $\mathrm{FeS}_{2}$ 晶须形成热液经历了快速降温, 缓慢降 温, 保温、逐渐平稳的物理过程. $\mathrm{FeS}_{2}$ 晶须生长早期 有负温度梯度和过冷出现, 晚期则是平稳的正温度 梯度状态.

(3) $\mathrm{FeS}_{2}$ 晶须生长时期组分浓度经历了早期极不 均匀, 中期阶段相对均匀, 晚期较均匀的变化过程.

(4) $\mathrm{FeS}_{2}$ 晶须生长时期, 早期界面状态极不稳定, 中期亚稳定, 晚期相对稳定. 界面状态的总体变化趋 势和过程是由不稳定状态向稳定状态转变.

(5) 耿庄 $\mathrm{FeS}_{2}$ 晶须微形貌是热液体系中温度、组 分浓度、界面相稳定性的协同作用结果.

从耿庄 $\mathrm{FeS}_{2}$ 晶须微形貌研究发现, 纳米-微米 $\mathrm{FeS}_{2}$ 晶须微形貌不仅反映出晶须生长时期热液体系 的物理、化学特点, 而且对界面相的稳定性特征反映 特别明显, 记录了晶须生长界面的变化过程. 由此可 见, 晶须微形貌研究, 在晶须生长过程研究方面有理 论和实践意义.

\section{参考文献}

1. Hansma P K, Tersoff J. Scanning tunneling microscopy. J Appl Phys, 1987, 61: 1-23 [doi]

2. Eggleston C M, Hochella M F Jr. Scanning tunneling microscopy of sulfide surface. Geochim Cosmochim Acta, 1990, 54: 15111517 [doi]

3. 廖立兵, 施倪承, 马喆生, 等. 方铅矿和辉钼矿表面的 STM 研究. 科学通报, 1991, 36: 606-608

4. Eggleston C M, hochella M F Jr. Scanning tunneling microscopy of pyrite $\{100\}$ surface structure and step reconstruction. Amer Mineral, 1992, 77: 221-224

5. 廖立兵, 施倪承, 马喆生, 等。䵢锡矿和赤铁矿表面的 STM 研究. 科学通报, 1992, 37: 1986-1989

6. 廖立兵, 马哲生, 施倪承, 等. 黄铁矿表面的扫描隧道显微镜研究. 地球科学-中国地质大学学报, 1994, 1: 39-42

7. 廖立兵，马晓霞，马哲生，等. 自然金 $\{110\}$ 晶面微形貌的 STM 观察. 矿物岩石, 1995, 2: 1-5

8. 廖立兵, 白春礼. 微斜长石(010)解理面的原子力显微镜研究. 矿物学报, 1996, 3: 242-244

9. 廖立兵, 马哲生, 施倪承. 单斜铜泡石 $\{001\}$ 解理面的 AFM 图像. 科学通报, 1996, 4: 341-342

10. 叶荣, 赵伦山, 马喆生, 等. 扫描隧道显微镜对黄铁矿表面微形貌的研究及成矿动力学意义. 科学通报, 1999, 11: 1220一1222

11. 张良钜, 雷威, 李东升, 等. 小秦岭金矿含金石英脉中石英晶体微形貌研究. 岩石矿物学杂志, 2003, 2: 177-180 
12. 张良钜. 小秦岭金矿含金石英脉中黄铁矿晶体的表面微形貌研究. 岩石矿物学杂志, 2004, 2: 167-172

13. 张良钜, 饶灿, 雷威. 九龙绿柱石晶体形貌研究. 矿物学报, 2005, 2: 191-196

14. 张良钜, 赵淑霞, 雷威, 等. 热液型水晶晶体形貌标型特征研究. 桂林工学院学报, 2005, 1: 133-134

15. 叶荣, 涂光炽, 马喆生, 等. 热液矿床矿物微形貌与晶体生长环境研究. 地学前缘, 2005, 2: 240一-246

16. Branner S S. The Growth and properties of whiskers. Science, 1958, 128: 569-575[doi]

17. Bonev I K, Reiche M, Marinov M, et al. Perfection and growth of natural pyrite whiskers and thin platelets. Phys Chem Miner, 1985 , 12: $223-232$ [doi]

18. Galuskin E. Winiarski-Antoni-Syngenetic whisker inclusions of pyrite in quartz Morphology, structure and composition. Neues Jahrbuch fuer Mineralogie. Monatshefte, 1997, 5: 229-240

19. Bonev I K, Garcia-Ruiz J M, Atanassova R, et al. Genesis of filamentary pyrite associated with calcite crystals. Eur J Mineral, 2005, 17: 905-913[doi]

20. 黄菲, 金成洙，边为民，等。山西耿庄金矿 $\mathrm{FeS}_{2}-\mathrm{Fe}(\mathrm{Ni}, \mathrm{Co}) \mathrm{S} 2$ 晶须的发现与成因探讨. 矿物学报, 2004, 4: 429-434

21. 黄菲, 金成洙, 姚玉增, 等。山西耿庄金矿重晶石巨晶中多相态包裹体研究. 吉林大学学报(地球科学版), 2005, 3: 313一-319

22. 黄菲, 金成洙, 边为民, 等. 重晶石巨晶中 $\mathrm{FeS}_{2}-\mathrm{Fe}(\mathrm{Ni} 、 \mathrm{Co}) \mathrm{S} 2$ 晶须微观形貌多样性及研究意义一一以山西耿庄金矿为例. 地 学前缘, 2005, 2: 142

23. 黄菲, 金成洙, 姚玉增, 等. 山西耿庄金矿区晶须状 $\mathrm{FeS}_{2}-\mathrm{Fe}(\mathrm{Ni} 、 \mathrm{Co}) \mathrm{S} 2$ 的显微形态与生长机理分析. 矿物学报, 2006, 3: 312一 316

24. 黄菲, 金成洙, 姚玉增, 等. 耿庄金矿 $\mathrm{FeS}_{2}-\mathrm{Fe}(\mathrm{Ni}, \mathrm{Co}) \mathrm{S} 2$ 系列晶须的特征及研究意义. 矿物岩石地球化学通报, 2005, 24(增刊): $85-86$

25. 陈敬中. 纳米科技的发展与纳米矿物学研究. 地质科技情报, 1994, 2: 32-38

26. 银剑钊. 纳米矿床学. 地学前缘, 1994, 1: 3-4

27. 叶英, 沈忠悦, 肖旦红, 等. 天然纳米-亚微米矿物堆积体: 一种典型的非传统矿产资源. 地球物理学进展, 2002, 17: 653654

28. 廖宗廷, 袁媛. 纳米科技与矿床学研究. 铜业工程, 2004, 3: $1-4$

29. 刘德良, 杨强, 李王晔, 等. 咣庐断裂南段韧性剪切带糜棱岩中纳米级颗粒的发现. 科学技术与工程, 2004, 1: 44一-45

30. Hirth J P, Pound G M. Whisker growth theory \& kinetics: Condensation and evaporation. Prog Mater Sci, 1963

31. 陈敬中．现代晶体化学一一理论与方法．北京：高等教育出版社, 2001.126-140 